\title{
Study on Evolutionary Path of University Students' Entrepreneurship Training
}

\author{
Daojian Yang and Xicang Zhao \\ School of Management, Jiangsu University, Zhenjiang, Jiangsu Province 212013, China \\ Correspondence should be addressed to Daojian Yang; 15785907@qq.com
}

Received 15 February 2014; Accepted 21 April 2014; Published 22 May 2014

Academic Editor: Jianguo Du

Copyright ( 2014 D. Yang and X. Zhao. This is an open access article distributed under the Creative Commons Attribution License, which permits unrestricted use, distribution, and reproduction in any medium, provided the original work is properly cited.

\begin{abstract}
Aiming at studying the evolution pattern of cultivating the ability of university students' entrepreneurship, this paper established the payoff matrix between the university and students agent with the evolutionary economics method. The analysis of the evolution of the communication process model reveals how the choice strategy of individuals influences that of groups. Numerical simulation also demonstrates the influences of different values of decision-making parameters and the change of initial conditions on the result of evolution. It is found that the evolution path system of university students' entrepreneurial ability has two kinds of modes: one is the ideal state; and the other one is the bad "lock" state. By adjusting parameters, we can jump out of the bad "lock" state, thus optimizing cultivation path.
\end{abstract}

\section{Introduction}

It has become a necessity for universities to cultivate students' entrepreneurial ability to adapt to the economic transformation and upgrading, as well as to the construction and development of entrepreneurial economy. It is also important to improve the education system in colleges and universities, strengthening the innovation training of entrepreneurial talent. With this progress, promoting the overall development of people and cultivating entrepreneurial qualities of a new generation can be achieved. Gorman et al. analyzed the literature about entrepreneurship education in the 10 years from 1985 to 1994 and point out that the cultivation of entrepreneurship for college students plays the function of entrepreneurship preparation and can enhance the individual's self-efficacy. During this process, universities should focus on the improvement of students' entrepreneurial qualities and skills [1]. Fayolle discussed the concept of entrepreneurial education and its theoretical framework, the pioneering education paradigm, entrepreneurship education mode, education assessment, target, function, interdisciplinary approach, and so forth, putting forward the innovative teaching mode to enhance the level of entrepreneurship [2]. O'Connor believes that entrepreneurial talent training is an effective mean of promoting economic development [3].
Research on college students' entrepreneurial ability training was mainly concentrated on the content of entrepreneurship education and entrepreneurial ability training mode. For entrepreneurial education content, Harrison and Leitch's research "Entrepreneurship and Leadership: education and enlightenment" has paved the way for the research on entrepreneurship education content [4]. Jack and Anderson find that entrepreneurship education activity involves the areas of science and art, which need to research entrepreneurship education theory to connect the gap between science and art [5]. Fiet studied the theoretical dimension of teaching entrepreneurship, emphasizing that more attention should be paid to the teaching of entrepreneurship theory [6]. Kent and Anderson argue that the spirit of cooperation, social ability, and pioneering consciousness should be put into the training content of entrepreneurship education [7]; some other scholars suggest "business failure" as one part of entrepreneurial education [8]. Sudharson et al. tried to wake up all engineering students' entrepreneurial ideas and inspire their entrepreneurial spirit, so in the original curriculum system, they design to added a few additional modules about entrepreneurship [9]. For entrepreneurial ability training mode, Johannisson et al. make an analysis of kolb's learning mode. Through the test of entrepreneurial action, they found that different groups (engineering students, 
TABLE 1: Payoff matrix of universities and students' strategy.

\begin{tabular}{lcc}
\hline & & Students \\
& Participation $N_{Y}$ & No participation $N_{N}$ \\
\hline Universities & & \\
Positive training $M_{Y}$ & $\alpha\left(\gamma_{S 1}-1\right) C_{S}-C_{C},\left(\gamma_{S 1}-1\right) C_{S}$ & $-C_{C},\left(\gamma_{S 2}-1\right) C_{S}$ \\
Negative training $M_{N}$ & $\alpha\left(\gamma_{S 3}-1\right) C_{S},\left(\gamma_{S 3}-1\right) C_{S}$ & $0,\left(\gamma_{S 2}-1\right) C_{S}$ \\
\hline
\end{tabular}

business school students, and the business operators) have different study effects [10]. Fiet explored the teaching dimension of entrepreneurship theory, finding that there exist some challenges for the research and education of entrepreneurship. When entrepreneurship teaching becomes predictable, teaching cannot achieve good results. He holds that entrepreneurship education should be based on the theory of entrepreneurship [6]. Above all, the existing studies are mainly carried out from the perspective of education partschools - to cultivate the ability of entrepreneurship, but they ignore the entrepreneurial ability training process, which is the mutual process of university and college students.

Evolutionary game theory combines the game theory with dynamic evolution process. It is the result of biological evolutionary theory. The analysis of the system of social habits, specification, or spontaneous formation and influence factors has made remarkable achievements. In fact, due to the insufficient understanding of entrepreneurial ability, too much attention has been focused on the theory, less on cultivating the ability of entrepreneurship; thus, problems exist. In this case, this paper is intended to discuss how to make both universities and students evolve in an expected way (inspiring and guiding students' entrepreneurial ability) so as to improve the training effectiveness of students' entrepreneurial ability.

\section{Model Building}

In constructing an evolutionary game model, we must make some basic assumptions of behavior interaction between university and college students, up to the present status of the management of universities. The two sides are the university and students, respectively, with both sides having limited rationality. The group-colleges and universities have two strategies: one is to actively develop the students' ability of entrepreneurship through various channels, hereinafter referred to as "positive training," remembered as $M_{Y}$ and the other strategy is negative cultivation of college students' entrepreneurial ability, which means universities do not even do anything, which is referred to as "negative training," remembered as $M_{N}$. Strategy community of university is set as $S_{C}$ \{positive training, $M_{Y}$; negative training, $M_{N}$ \}. The group-students also have two strategies: one is actively participating in activities to develop their entrepreneurial skills, hereinafter referred to as "participation," remembered as $N_{Y}$, while the second strategy is not involved in their activities that develop their entrepreneurial skills, hereinafter referred to as "no participation," noted as $N_{N}$. The strategy of university student group is set as $S_{S}$ \{participation, $N_{Y}$ and no participation, $\left.N_{N}\right\}$.

If universities actively cultivate their students' entrepreneurial ability, they will improve the system of entrepreneurship education management and entrepreneurship education system and create entrepreneurship training base and so on. The cost of these activities is set as $C_{C}$.

If students are actively involved in developing their entrepreneurial ability, they need to spend the costs of time and energy, set as $C_{S}$.

When universities are active in entrepreneurial ability training and students are also active in developing their business ability, students will increase their human capital value, and their costs will have higher returns $\gamma_{S 1}, \gamma_{S 1} \geq 1$. At this point, the net income for the students is $\left(\gamma_{S 1}-1\right) C_{S}$. The net income of colleges and universities is $\alpha\left(\gamma_{S 1}-1\right) C_{S}-$ $C_{C}$, where $\alpha$ is the reputation and alumni support through cultivating high level students for colleges and universities, and $0 \leq \alpha \leq 1$. If students do not participate in developing the ability of business, they can spare the time and energy in other activities, so at this time, the investment rate of return is $\gamma_{S 2}$, and $\gamma_{S 2} \leq \gamma_{S 1}$. At this point, the net income for the students is $\left(\gamma_{S 2}-1\right) C_{S}$ and the net income of universities is $-C_{C}$.

When universities are negative in cultivating the students' entrepreneurial ability, students can promote entrepreneurship ability through self-study or internship. Without the help, support, and guidance of universities, the rate of return on its investment is lower, set as $\gamma_{S 3}, \gamma_{S 3} \leq \gamma_{S 2}$. At this point, the net income for the students is $\left(\gamma_{S 3}-1\right) C_{S}$ and the net income of universities is $\alpha\left(\gamma_{S 3}-1\right) C_{S}$. If students themselves do not actively promote entrepreneurship ability but spend the time and energy in other activities, the net income for the students would be $\left(\gamma_{S 2}-1\right) C_{S}$, and the net income of universities is 0 .

Based on the above assumptions, we constructed the strategy payoff matrix between the universities and students, as shown in Table 1.

\section{The Evolution of the Model and Its Equilibrium Analysis}

3.1. The Evolution of the Model. Assume that, in the initial state, the proportion of universities choosing $M_{Y}$ is $p$ and that the proportion of universities choosing strategy $M_{N}$ is $1-p$; the proportion of students choosing strategy $N_{Y}$ is $q$; then, the proportion of students choosing $N_{N}$ is $1-q$. Here we calculate the corresponding expected revenue and average income. 
TABLE 2: Local stability analysis results.

\begin{tabular}{lccccc}
\hline Equilibrium point & Det $J$ & & Tr & Result \\
\hline$p=0, q=0$ & $-C_{C}\left(\gamma_{S 3}-\gamma_{S 2}\right) C_{S}$ & + & $-C_{C}+\left(\gamma_{S 3}-\gamma_{S 2}\right) C_{S}$ & ESS \\
$p=0, q=1$ & $-\left[\alpha\left(\gamma_{S 1}-\gamma_{S 3}\right) C_{S}-C_{C}\right]\left(\gamma_{S 3}-\gamma_{S 2}\right) C_{S}$ & + & $\alpha\left(\gamma_{S 1}-\gamma_{S 3}\right) C_{S}-C_{C}-\left(\gamma_{S 3}-\gamma_{S 2}\right) C_{S}$ & + & Not stable \\
$p=1, q=0$ & $C_{C}\left(\gamma_{S 1}-\gamma_{S 2}\right) C_{S}$ & + & $C_{C}+\left(\gamma_{S 1}-\gamma_{S 2}\right) C_{S}$ & + & Not stable \\
$p=1, q=1$ & {$\left[\alpha\left(\gamma_{S 1}-\gamma_{S 3}\right) C_{S}-C_{C}\right]\left(\gamma_{S 1}-\gamma_{S 2}\right) C_{S}$} & + & $-\left[\alpha\left(\gamma_{S 1}-\gamma_{S 3}\right) C_{S}-C_{C}\right]-\left(\gamma_{S 1}-\gamma_{S 2}\right) C_{S}$ & - & ESS \\
$p=p^{*}, q=q^{*}$ & $-p^{*} q^{*}\left(1-p^{*}\right)\left(1-q^{*}\right) \alpha\left(\gamma_{S 1}-\gamma_{S 3}\right)^{2} C_{S}{ }^{2}$ & - & 0 & saddle point \\
\hline
\end{tabular}

$U_{1}$ is the expected return of the selection of universities to $M_{Y}$ strategy; $U_{2}$ is the expected return of universities choosing $M_{N}$ strategy; $\bar{U}$ is the average income of universities. Consider the following:

$$
\begin{aligned}
U_{1} & =q\left[\alpha\left(\gamma_{S 1}-1\right) C_{S}-C_{C}\right]+(1-q)\left(-C_{C}\right) \\
& =q \alpha\left(\gamma_{S 1}-1\right) C_{S}-C_{C}, \\
U_{2} & =q \alpha\left(\gamma_{S 3}-1\right) C_{S}, \\
\bar{U} & =p U_{1}+(1-p) U_{2} .
\end{aligned}
$$

Similarly, $V_{1}$ is the expected return of students choosing $N_{Y}$ strategy; $V_{2}$ is the expected return for students choosing $N_{N}$ strategy; $\bar{V}$ is the average income for students. Consider the following:

$$
\begin{aligned}
V_{1} & =p\left(\gamma_{S 1}-1\right) C_{S}+(1-p)\left(\gamma_{S 3}-1\right) C_{S} \\
& =p\left(\gamma_{S 1}-\gamma_{S 3}\right) C_{S}+\left(\gamma_{S 3}-1\right) C_{S}, \\
V_{2} & =\left(\gamma_{S 2}-1\right) C_{S}, \\
\bar{V} & =q V_{1}+(1-q) V_{2} .
\end{aligned}
$$

$$
\begin{aligned}
J & =\left[\begin{array}{cc}
\frac{d F(p)}{d p} & \frac{d F(p)}{d q} \\
\frac{d F(q)}{d p} & \frac{d F(q)}{d q}
\end{array}\right] \\
& =\left[\begin{array}{c}
(1-2 p)\left[q \alpha\left(\gamma_{S 1}-\gamma_{S 3}\right) C_{S}-C_{C}\right] \\
q(1-q)\left(\gamma_{S 1}-\gamma_{S 3}\right) C_{S}
\end{array}\right.
\end{aligned}
$$

$\left.\begin{array}{c}p(1-p) \alpha\left(\gamma_{S 1}-\gamma_{S 3}\right) C_{S} \\ (1-2 q)\left[p\left(\gamma_{S 1}-\gamma_{S 3}\right) C_{S}+\left(\gamma_{S 3}-\gamma_{S 2}\right) C_{S}\right]\end{array}\right]$

$$
\begin{aligned}
F(p) & =\frac{d p}{d t}=p\left(U_{1}-\bar{U}\right) \\
& =p(1-p)\left[q \alpha\left(\gamma_{S 1}-\gamma_{S 3}\right) C_{S}-C_{C}\right], \\
F(q) & =\frac{d q}{d t}=q(V-\bar{V}) \\
& =q(1-q)\left[p\left(\gamma_{S 1}-\gamma_{S 3}\right) C_{S}+\left(\gamma_{S 3}-\gamma_{S 2}\right) C_{S}\right] .
\end{aligned}
$$

Through (3), we can study the evolution of the interaction behavior between universities and students. Mark the Jacobian matrix of (3) as $J$ which is expressed by
The determinant of the Jacobian matrix is marked as Det $J$, and the trace of the Jacobian matrix is marked as Tr. Consider

$$
\begin{aligned}
\text { Det } J= & (1-2 p)(1-2 q)\left[q \alpha\left(\gamma_{S 1}-\gamma_{S 3}\right) C_{S}-C_{C}\right] \\
& \times\left[p\left(\gamma_{S 1}-\gamma_{S 3}\right) C_{S}+\left(\gamma_{S 3}-\gamma_{S 2}\right) C_{S}\right] \\
& -p q(1-p)(1-q) \alpha\left(\gamma_{S 1}-\gamma_{S 3}\right)^{2} C_{S}^{2}, \\
\operatorname{Tr}= & (1-2 p)\left[q \alpha\left(\gamma_{S 1}-\gamma_{S 3}\right) C_{S}-C_{C}\right] \\
& +(1-2 q)\left[p\left(\gamma_{S 1}-\gamma_{S 3}\right) C_{S}+\left(\gamma_{S 3}-\gamma_{S 2}\right) C_{S}\right] .
\end{aligned}
$$

3.2. Equilibrium and Its Stability Analysis. Since $p$ and $q$, respectively, represent the proportion of universities' and students' choices of the strategies above, it is drawn that $0 \leq$ $p \leq 1,0 \leq q \leq 1$. On a plane $M^{*}=\{(p, q) \mid 0 \leq p, q \leq 1\}$, the system has 5 equilibrium points: $(0,0),(0,1),(1,0),(1,1)$, and $\left(p^{*}, q^{*}\right)$. Among them, $p^{*}=\left(\gamma_{S 2}-\gamma_{S 3}\right) /\left(\gamma_{S 1}-\gamma_{S 3}\right)$ and $q^{*}=C_{C} / \alpha\left(\gamma_{S 1}-\gamma_{S 3}\right) C_{S}$. According to the Jacobian matrix, we can have the local buckling analysis results in Table 2.

According to Table $2,\left(p^{*}, q^{*}\right)$ is the saddle point, and $(0,1)$ and $(1,0)$ are the instability points. $(0,0)$ and $(1,1)$ are the evolutionary stable strategy, corresponding to the modes $\left(M_{N}, N_{N}\right)$ and $\left(M_{Y}, N_{Y}\right)$. Here, $\left(M_{N}, N_{N}\right)$ means the university and students both choose negative action, which 


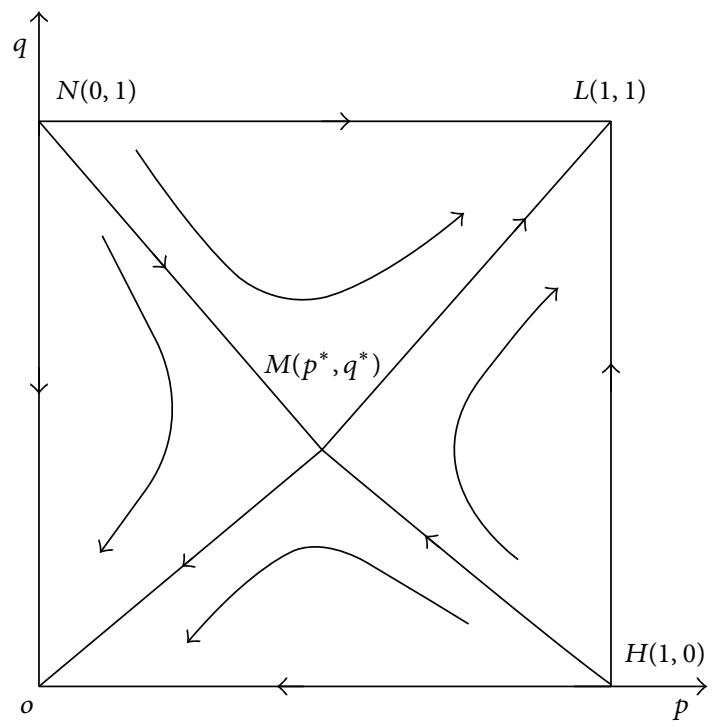

FIGURE 1: Systematic dynamic evolution.

is badly locked; $\left(M_{Y}, N_{Y}\right)$ means the university and students choose positive action, which is an ideal condition. Figure 1 shows the strategy communication process of university and students groups.

\section{The Influence of Parameter Change on the Convergence System}

(1) The impact of $C_{C}, \alpha$ and $C_{S}$ on the system convergence

In the saddle point, $\partial p / \partial C_{C}=0, \partial q / \partial C_{C}=1 / \alpha\left(\gamma_{S 1}-\right.$ $\left.\gamma_{S 3}\right) C_{S}>0$. When other parameters remain constant, $C_{C}$ increases, $\alpha$ or $C_{S}$ decreases, and saddle point goes upward vertically. The probability of converging to mode $\left(M_{N}, N_{N}\right)$ increases, and the probability of convergence to $\left(M_{Y}, N_{Y}\right)$ decreases; on the contrary, the probability of converging to mode $\left(M_{N}, N_{N}\right)$ is reduced, and the probability of convergence to $\left(M_{Y}, N_{Y}\right)$ increases, which is shown in Figure 2.

(2) The impact of $\gamma_{S 1}$ on the system convergence

In the saddle point, $\partial p / \partial \gamma_{S 1}=-\left(\gamma_{S 2}-\gamma_{S 3}\right) /\left(\gamma_{S 1}-\gamma_{S 2}\right)^{2}<$ $0, \partial q / \partial \gamma_{S 1}=-C_{C} / \alpha\left(\gamma_{S 1}-\gamma_{S 3}\right)^{2} C_{S}<0$. When the other parameters remain constant, $\gamma_{S 1}$ increases, and saddle point moves to the lower left corner, so the probability of converging to mode $\left(M_{N}, N_{N}\right)$ is reduced, and the probability of convergence in $\left(M_{Y}, N_{Y}\right)$ increases; on the contrary, the probability of converging to mode $\left(M_{N}, N_{N}\right)$ increases, and the probability of convergence in $\left(M_{Y}, N_{Y}\right)$ is reduced, which is shown in Figure 3.

(3) The impact of $\gamma_{S 2}$ on the system convergence

In the saddle point, $\partial p / \partial \gamma_{S 2}=1 /\left(\gamma_{S 1}-\gamma_{S 2}\right)>0, \partial q / \partial \gamma_{S 2}=$ 0 . When the other parameters remain constant, $\gamma_{S 2}$ increases, and saddle point moves to the right corner, so the probability of converging to mode $\left(M_{N}, N_{N}\right)$ increases, and the probability of convergence in $\left(M_{Y}, N_{Y}\right)$ decreases; on the contrary, the probability of converging to mode $\left(M_{N}, N_{N}\right)$ reduces, and the probability of convergence in $\left(M_{Y}, N_{Y}\right)$ increases, which is shown in Figure 4.
(4) The impact of $\gamma_{S 3}$ on the system convergence

In the saddle point, $\partial p / \partial \gamma_{S 3}=-1 /\left(\gamma_{S 1}-\gamma_{S 2}\right)<$ $0, \partial q / \partial \gamma_{S 3}=C_{C} / \alpha\left(\gamma_{S 3}-\gamma_{S 1}\right)^{2} C_{S}>0$. When the other parameters remain constant, $\gamma_{S 3}$ increases, and the saddle point moves to the top left; on the contrary, the saddle point moves to the lower right, as is shown in Figure 5. The impact of $\gamma_{S 3}$ on the results of the convergence system is not clear, which needs further numerical analysis.

\section{The Result Analysis of Numerical Experiments}

In behavior strategy communication system between university and students, some parameters are involved: the proportion of initial population $p$ and $q$, the respective cost of college and students $C_{C}$ and $C_{S}$, the rate of reward $\gamma_{S 1}, \gamma_{S 2}$, and $\gamma_{S 3}$ of students under different situations, and reward coefficient $\alpha$ of universities. These parameters will influence the earnings of university and students, which will further influence the evolution of the system.

(1) The impact of the changes of $p_{0}$ and $q_{0}$ on the result of system evolution

According to the numerical experiment shown in Figure $6, p_{0}$ and $q_{0}$, respectively, represent the proportion of the initial population that university chooses $M_{Y}$ and students who choose $N_{Y}$. Parameter values are $C_{C}=1, C_{S}=$ $10, \alpha=0.2, \gamma_{S 1}=2, \gamma_{S 2}=1.5$, and $\gamma_{S 3}=1.2$. It can be seen from Figure 6 the dependence of the path when university and students are in the process of behavior strategy interaction. With different initial ratio the convergence curves do not overlap before reaching their equilibrium. Convergence speed is influenced not only by the initial proportion students choosing to have entrepreneurial ability training, but also by the initial proportion that students have related actions to improve their entrepreneurial abilities at the same time. The closer the proportion gets to the equilibrium, the faster the convergence speed is. As long as the proportion of initial $M_{Y}$ strategy use is very low (e.g., $p_{0}=0.1$ ), the system will eventually be locked in a "bad" state; if this proportion is very high (e.g., $p_{0}=0.9$ ), the system can eventually evolve to the ideal mode $\left(M_{Y}, N_{Y}\right)$. In general circumstances, as the proportion of students choosing to have positive action increases, it will also help the system evolve toward the ideal mode; therefore, universities must first enhance the entrepreneurship education actively, arousing the students' enthusiasm.

(2) The impact of the change of $C_{C}$ on the result of system evolution

Numerical test results of the impact are shown in Figure 7. The reason that we set the proportion of students taking part in the entrepreneurship activities as 0.4 is that as the impact of the change of the initial population on the evolution is analyzed above, it is clear that when the initial choice ratio of universities' cultivating students' entrepreneurship is high, the system will converge to $\left(M_{Y}, N_{Y}\right)$ mode; if the initial choice ratio of universities' cultivating students' entrepreneurship is lower, the system will converge to mode $\left(M_{N}, N_{N}\right)$. So $q=0.4$ is a typical situation. At the same time, combining 


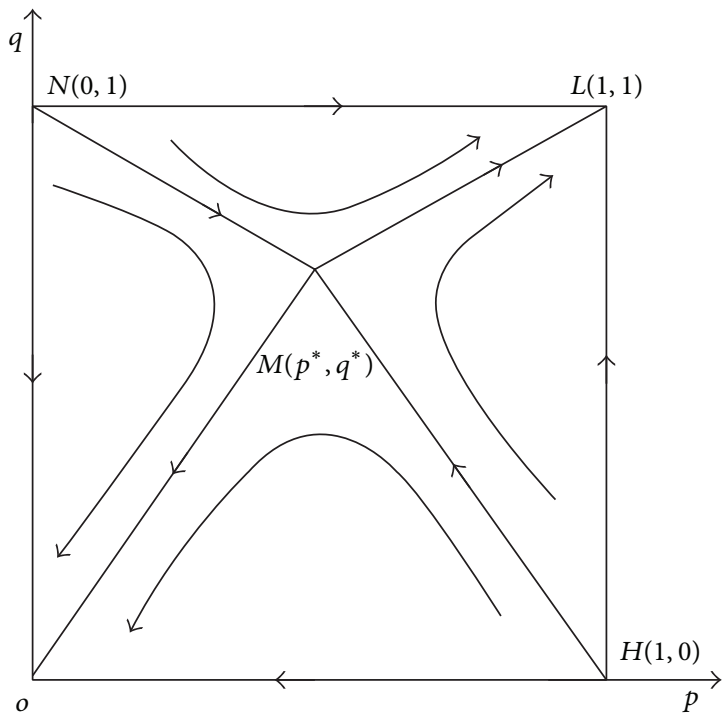

(a) The situation of $C_{C}$ increases, $\alpha$ or $C_{S}$ decreases

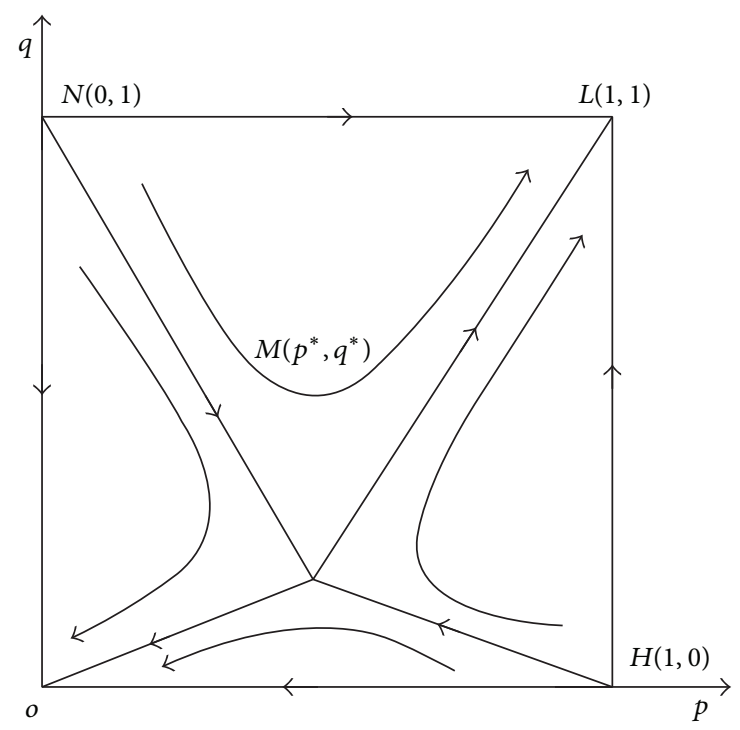

(b) The situation of $C_{C}$ decreases, $\alpha$ or $C_{S}$ increases

FIgURE 2: The impact of $C_{C}, \alpha, C_{S}$ on the system convergence.

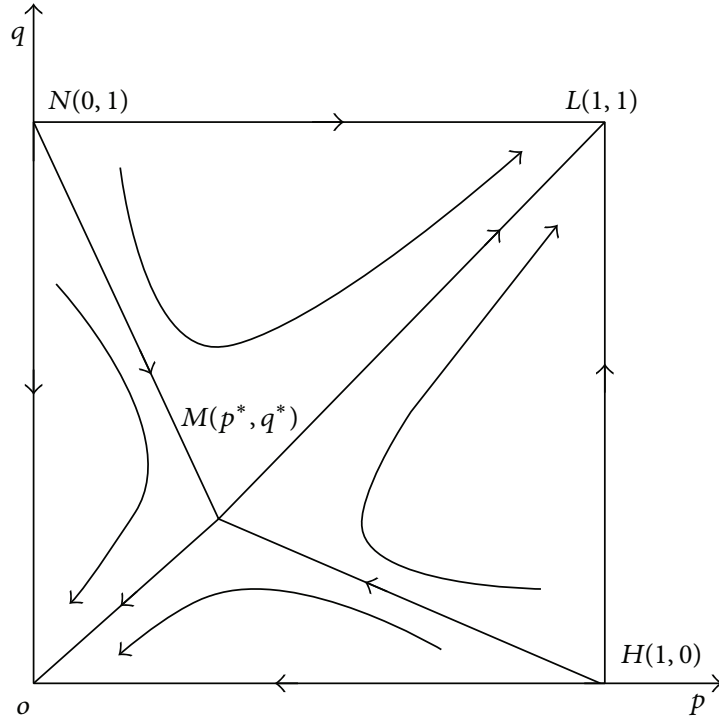

(a) The situation when $\gamma_{S 1}$ increases

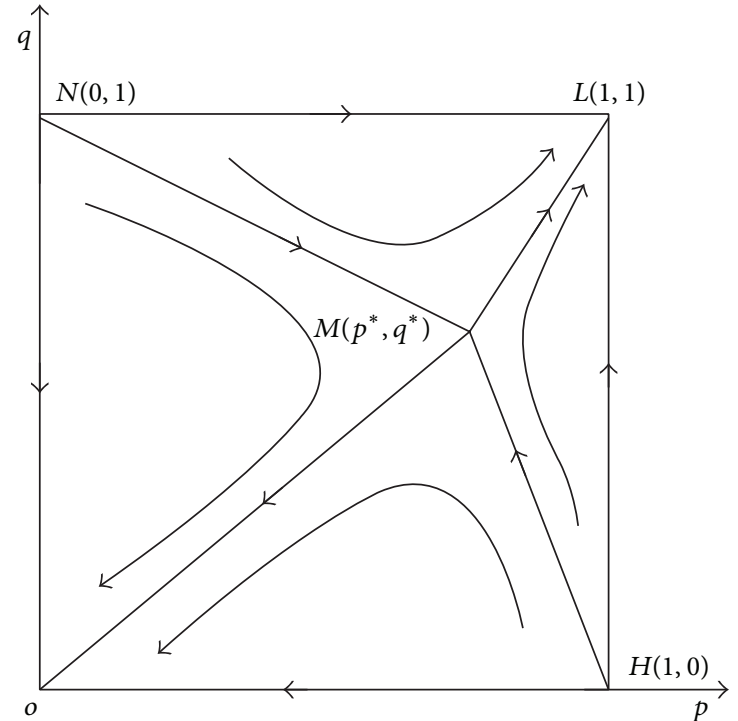

(b) The situation when $\gamma_{S 1}$ decreases

FIGURE 3: The impact of $\gamma_{S 1}$ on the system convergence.

the fact that the overall university students are in high enthusiasm but with lower ability in entrepreneurial activities (national college students entrepreneurship research report shows that $14 \%$ of students participated in a training program or entrepreneurship competition and that $48.8 \%$ of college students hope to be provided with business related professional training) and choosing $q=0.4$, which is more in line with the actual situation, other parameter values are as follows: $C_{S}=10, \alpha=0.2, \gamma_{S 1}=2, \gamma_{S 2}=1.5$, and $\gamma_{S 3}=1.2$.

As Figure 7 shows, with the increase of university's training cost $C_{C}$, the convergence speed of the system slows down and the time of convergence to equilibrium mode increases, and the system's evolutionary direction converts from mode $\left(M_{Y}, N_{Y}\right)$ to a bad lock mode $\left(M_{N}, N_{N}\right)$. Universities' training cost represents the burden of entrepreneurship training of universities. Under the certain level of total cost of entrepreneurship training, universities' burden should be eased by broadening the financing channels. This can not only guarantee the training level, but also arouse universities' training enthusiasm.

(3) The impact of the change of $C_{S}$ on the result of system evolution

The impact is shown in Figure 8. The parameter values are as follows: $q=0.4, C_{C}=1, \alpha=0.2, \gamma_{S 1}=$ 


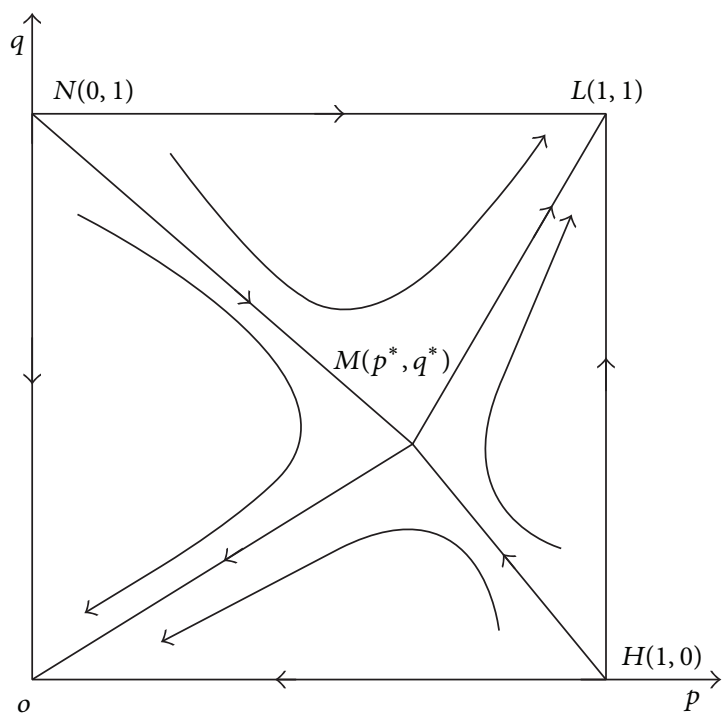

(a) The situation when $\gamma_{S 2}$ increases

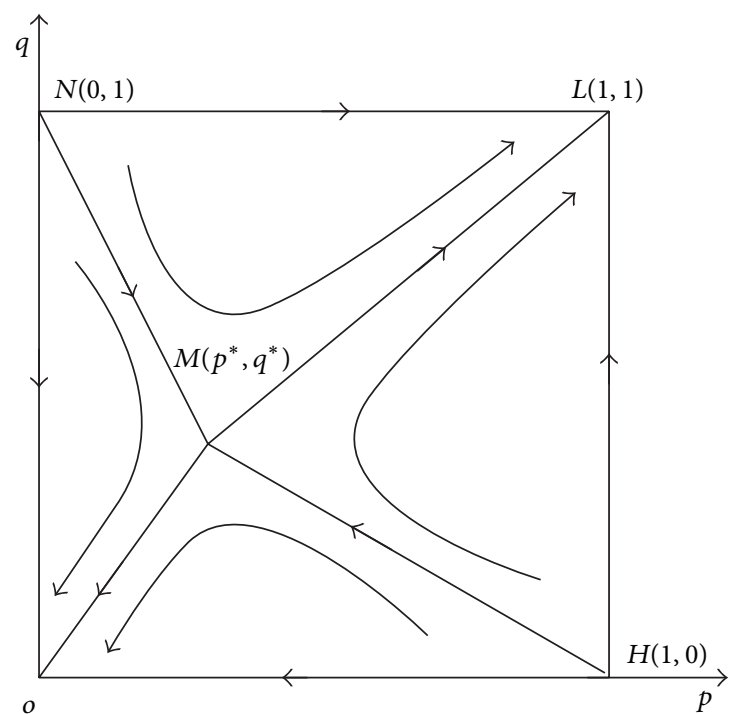

(b) The situation when $\gamma_{S 2}$ decreases

FIGURE 4: The impact of $\gamma_{S 2}$ on the system convergence.

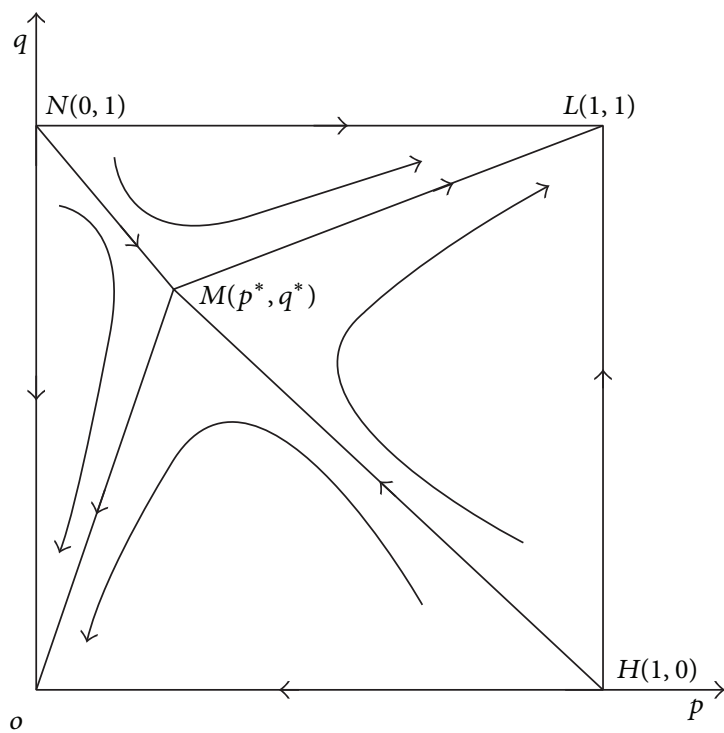

(a) The situation when $\gamma_{S 3}$ increases

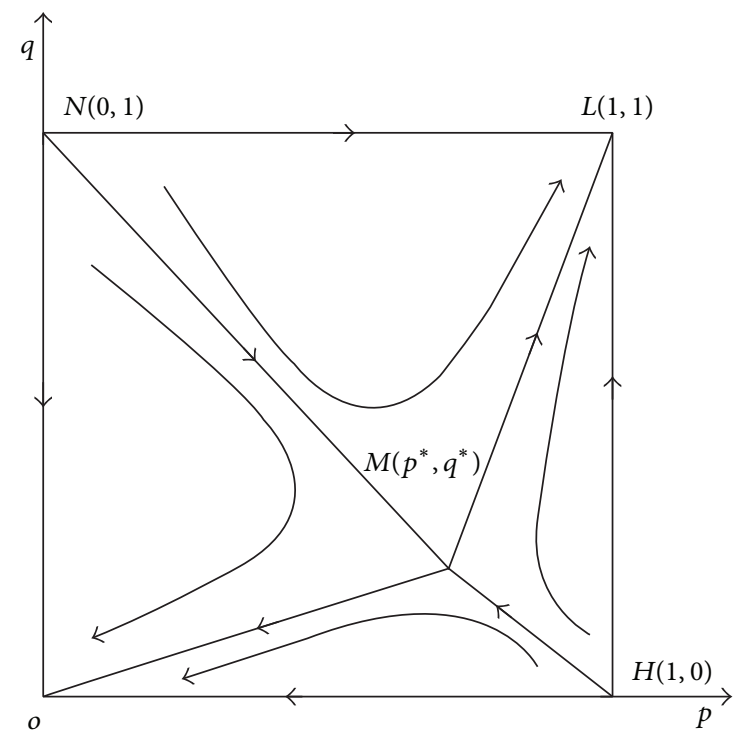

(b) The situation when $\gamma_{S 3}$ decreases

FIGURE 5: The impact of $\gamma_{S 3}$ on system convergence.

$2, \gamma_{S 2}=1.5$, and $\gamma_{S 3}=1.2$. It can be seen from Figure 8 that with the increase of students' entrepreneurial activity costs $C_{S}$, system convergence speeds up, and the time of converging to equilibrium mode reduces. The evolution direction of the system will also change from bad lock mode $\left(M_{N}, N_{N}\right)$ to the ideal mode $\left(M_{Y}, N_{Y}\right)$. The cost $C_{S}$ reflects the difficulty level of promoting entrepreneurship skills. We can see that more college students tend to participate in the school's entrepreneurial ability training program, rather than to choose self-study to gain their entrepreneurial skills. Therefore, in the process of entrepreneurship education, universities should pay more attention to the core and important business knowledge, while the simple and easy knowledge can be learned by students themselves. Universities need to distinguish between the focus of entrepreneurship education and the investment of education resources.

(4) The impact of the change of $\gamma_{S 1}$ on the result of system evolution

The impact is shown in Figure 9, and the parameter value selections are as follows: $q=0.4, C_{C}=1, C_{S}=10, \alpha=$ $0.2, \gamma_{S 2}=1.5, \gamma_{S 3}=1.2$.

As can be seen from Figure 9, with the increase of the investment return ratio $\gamma_{S 1}$ of students' entrepreneurial ability improvement, the system convergence speeds up, and the 

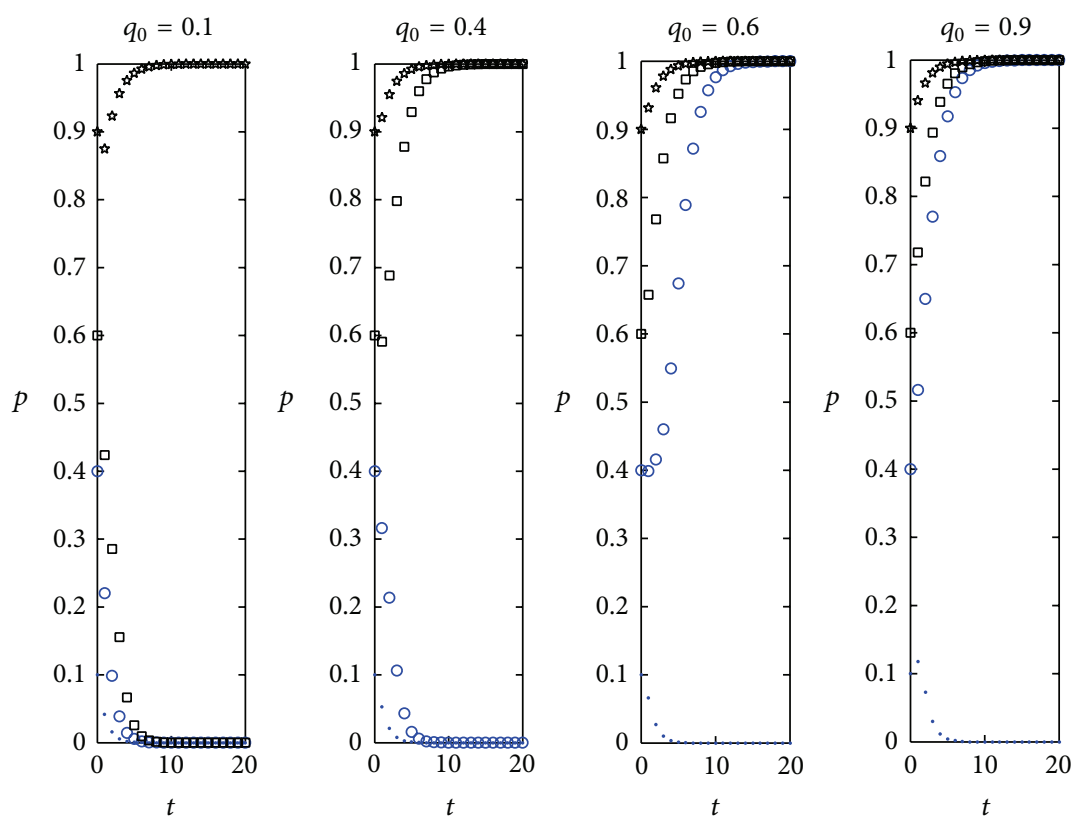

$$
\begin{array}{ll}
-p_{0} & =0.1 \\
\text { - } & p_{0}=0.4 \\
\text { - } p_{0}=0.6 \\
\text { - } p_{0}=0.9
\end{array}
$$

$$
\begin{array}{ll}
\text { - } p_{0}=0.1 \\
\text { - } p_{0}=0.4 \\
\text { - } p_{0}=0.6 \\
\text { * } p_{0}=0.9
\end{array}
$$

$$
\begin{aligned}
& \text { - } p_{0}=0.1 \\
& \text { - } p_{0}=0.4 \\
& \text { - } p_{0}=0.6 \\
& \text { - } p_{0}=0.9
\end{aligned}
$$$$
\text { - } p_{0}=0.1
$$$$
\text { ○ } p_{0}=0.4
$$$$
\text { ㅁ } p_{0}=0.6
$$$$
\text { * } p_{0}=0.9
$$

FIgURE 6: Impact of the change of $p_{0}$ and $q_{0}$ on the result of the system evolution.
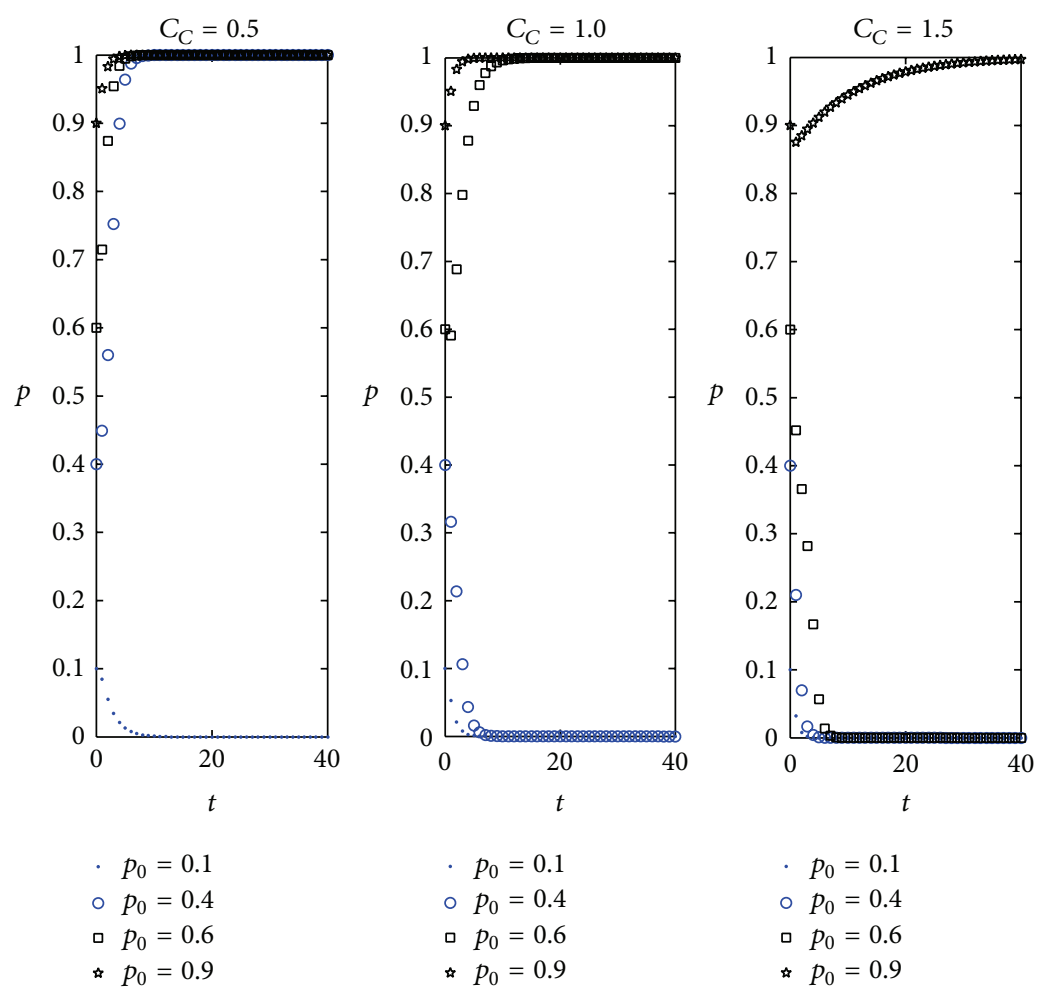

$\begin{aligned} & \cdot p_{0}=0.1 \\ & \circ p_{0}=0.4 \\ & \text { - } p_{0}=0.6 \\ & \text { औ } p_{0}=0.9\end{aligned}$

Figure 7: Impact of the changes of $C_{C}$ on the result of the system evolution. 

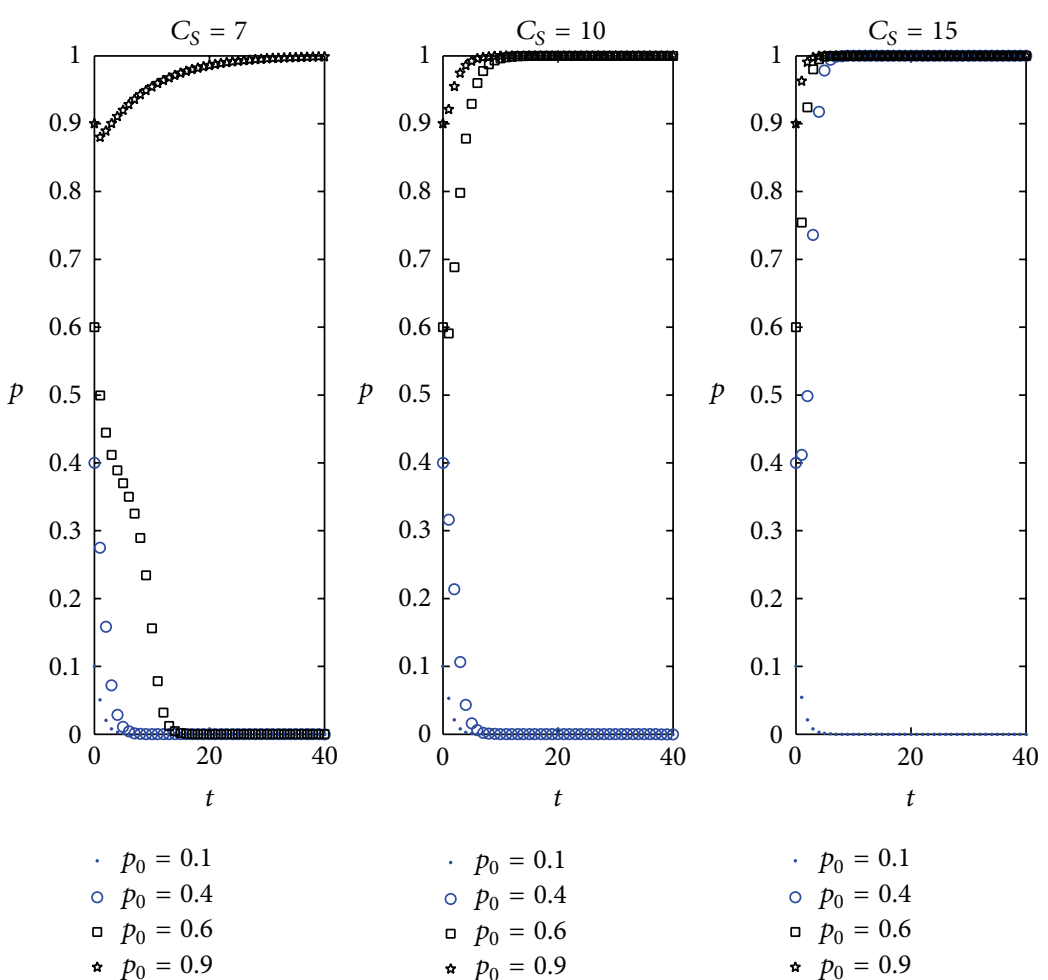

- $p_{0}=0.1$

- $p_{0}=0.4$

ㅁ $p_{0}=0.6$

* $p_{0}=0.9$

FIGURE 8: Impact of the changes of $C_{S}$ on the result of the system evolution.
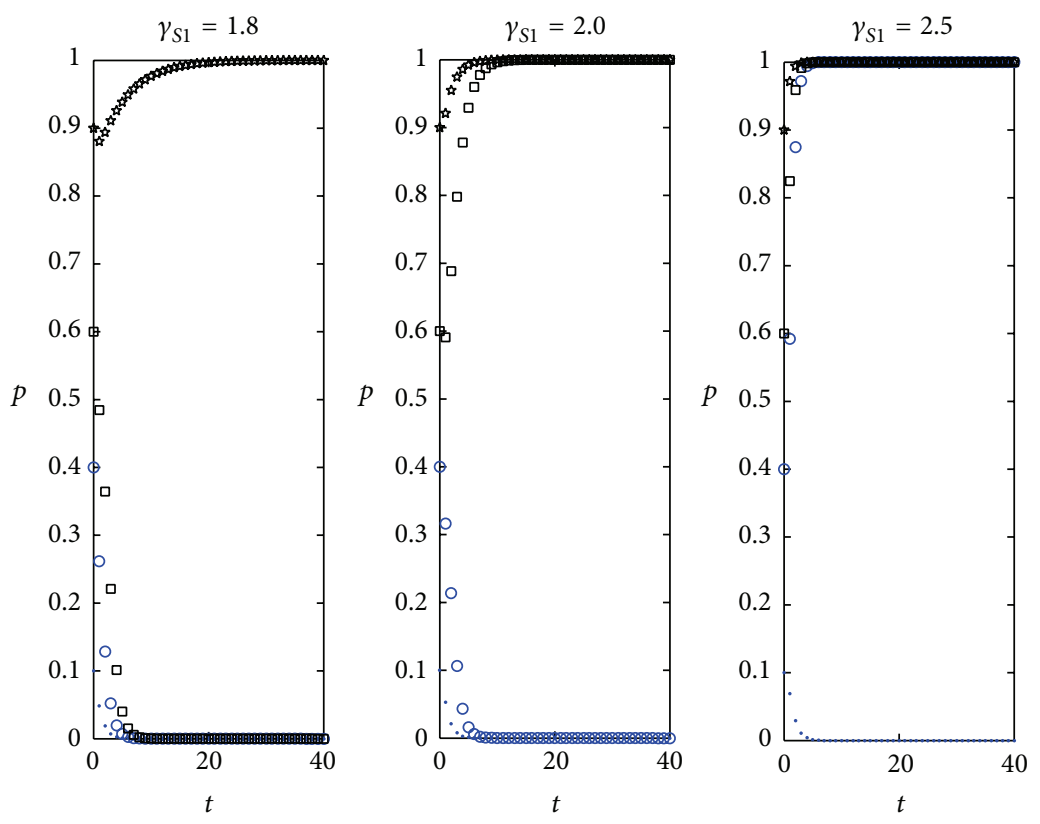

- $p_{0}=0.1$
- $p_{0}=0.4$
- $p_{0}=0.6$
\& $p_{0}=0.9$

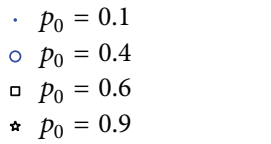

- $p_{0}=0.1$

- $p_{0}=0.4$

ㅁ $p_{0}=0.6$

* $p_{0}=0.9$

FIGURE 9: Impact of the change of $\gamma_{S 1}$ on the result of the system evolution. 

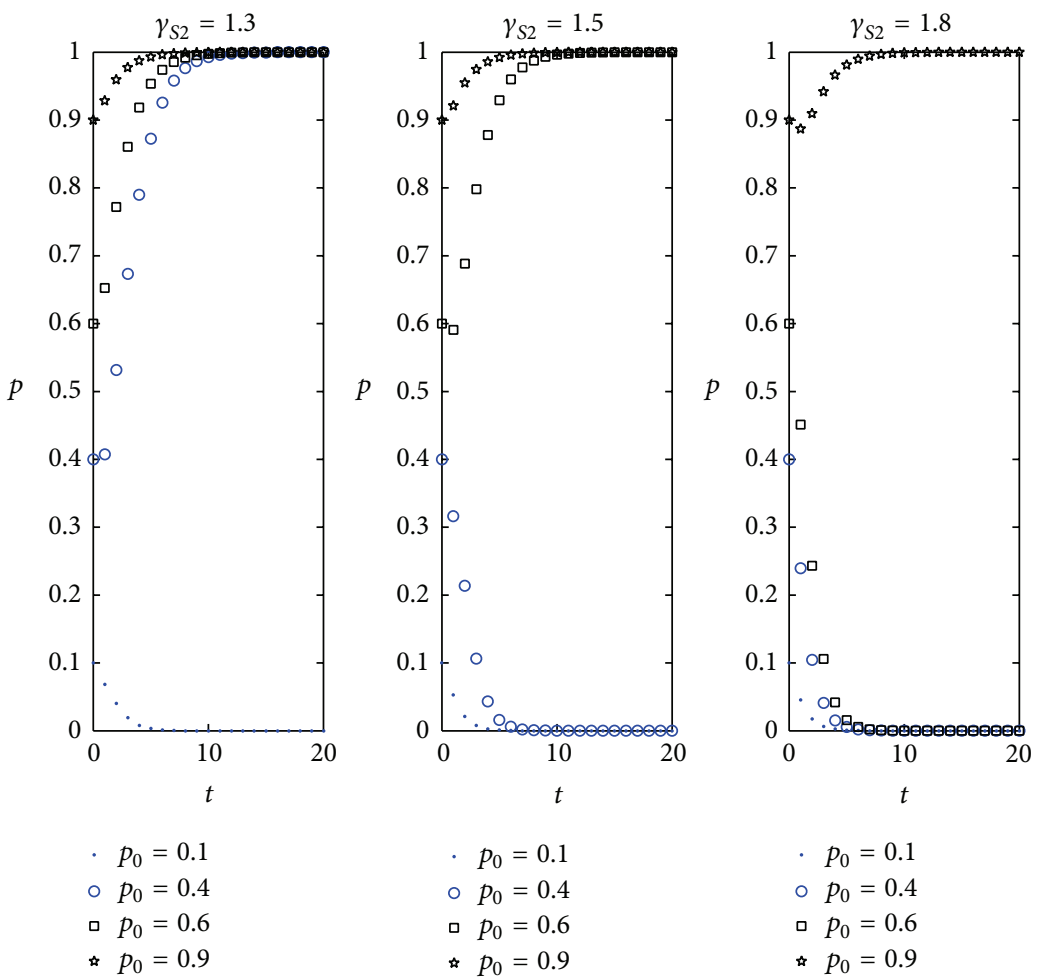

FIGURE 10: Impact of the change of $\gamma_{S 2}$ on the result of the system evolution.

evolution direction of the system will be changed from $\left(M_{N}, N_{N}\right)$ into the ideal mode $\left(M_{Y}, N_{Y}\right)$. Increasing $\gamma_{S 1}$ means that more entrepreneurial investment can lead to ability improvement and significant increase of their own human capital value. At the same time universities can also get high school reputation. In the condition of a higher $\gamma_{S 1}$, both universities and students tend to take positive action. Only when the investment return ratio is high enough, the enthusiasm of university students' participation will be high. Therefore, universities need to improve training effectiveness further to increase the investment return ratio of university students' entrepreneurial ability improvement.

(5) The impact of the change of $\gamma_{S 2}$ on the result of system evolution

The impact is shown in Figure 10, and the parameter value selections are as follows: $q=0.4, C_{C}=1, C_{S}=10, \alpha=$ $0.2, \gamma_{S 1}=2$, and $\gamma_{S 3}=1.2$.

Figure 10 indicates that the rate of system convergence increases with the growth of $\gamma_{S 2}$, with systematic evolution transforming from mode $\left(M_{Y}, N_{Y}\right)$ to mode $\left(M_{N}, N_{N}\right)$. So, when making decision on participating in entrepreneurship training or not, university students consider not only the investment return ratio, but also the opportunity costs of participation. It again showed that improvement training effectiveness further to increase the gains of university students' participation is the key to improve the students' enthusiasm to participate in the entrepreneurial ability training.

(6) The impact of the change of $\gamma_{S 3}$ on the result of system evolution

Figure 11 shows the influence of return rate $\gamma_{S 3}$ of enhancement of college students' entrepreneurial ability on system convergence. The parameters are listed as follows: $q=$ $0.4, C_{C}=1, C_{S}=10, \alpha=0.2, \gamma_{S 1}=2$, and $\gamma_{S 2}=1.5$.

We may find that, in Figure 11, the impact of $\gamma_{S 3}$ on systematic evolvement direction is similar to that of $\gamma_{S 1}$ on the system; the impact of $\gamma_{S 3}$ on system convergence rate, however, is more obvious. It becomes slow with the increase of $\gamma_{S 3} . p_{0}=0.4$ and $p_{0}=0.6$ evolve in the direction towards $\left(M_{N}, N_{N}\right)$ in the early periods and then in a short time they change towards $\left(M_{Y}, N_{Y}\right)$ and converge at $\left(M_{Y}, N_{Y}\right)$.

Further analysis finds that $\gamma_{S 1}, \gamma_{S 2}$, and $\gamma_{S 3}$ are decided by the values of $\gamma_{S 1}-\gamma_{S 3}$ and $\gamma_{S 2}-\gamma_{S 3}$, which are further decided by the balance of return rate and return rate of time and energy used in other field, with or without assistance by universities. A larger balance between $\gamma_{S 1}$ and $\gamma_{S 2}$ brings the evolvement to $\left(M_{Y}, N_{Y}\right)$ in the ideal stage. But a larger balance between $\gamma_{S 2}$ and $\gamma_{S 3}$ brings $\left(M_{Y}, N_{Y}\right)$ more to a bad lock mode. Anyway, higher investment of entrepreneurship training leads to easier involvement to ideal mode. Hence, higher education institutions should take more efforts to enhance the efficiency in talent education so as to increase the reward rate of students' participation in the education.

(7) The impact of $\alpha$ on the result of system evolution

Figure 12 shows the influence of return coefficient $\alpha$ of university entrepreneurship training on system convergence. Parameters are listed as follows: $q=0.4, C_{C}=1, C_{S}=$ $10, \gamma_{S 1}=2, \gamma_{S 2}=1.5$, and $\gamma_{S 3}=1.2$.

Figure 12 shows that, with the increase of return coefficient $\alpha$, system converges faster to the ideal mode $\left(M_{Y}, N_{Y}\right)$ and the system will change toward the ideal mode. In colleges and universities, the purpose of entrepreneurship education and entrepreneurial ability is mainly to relieve employment 

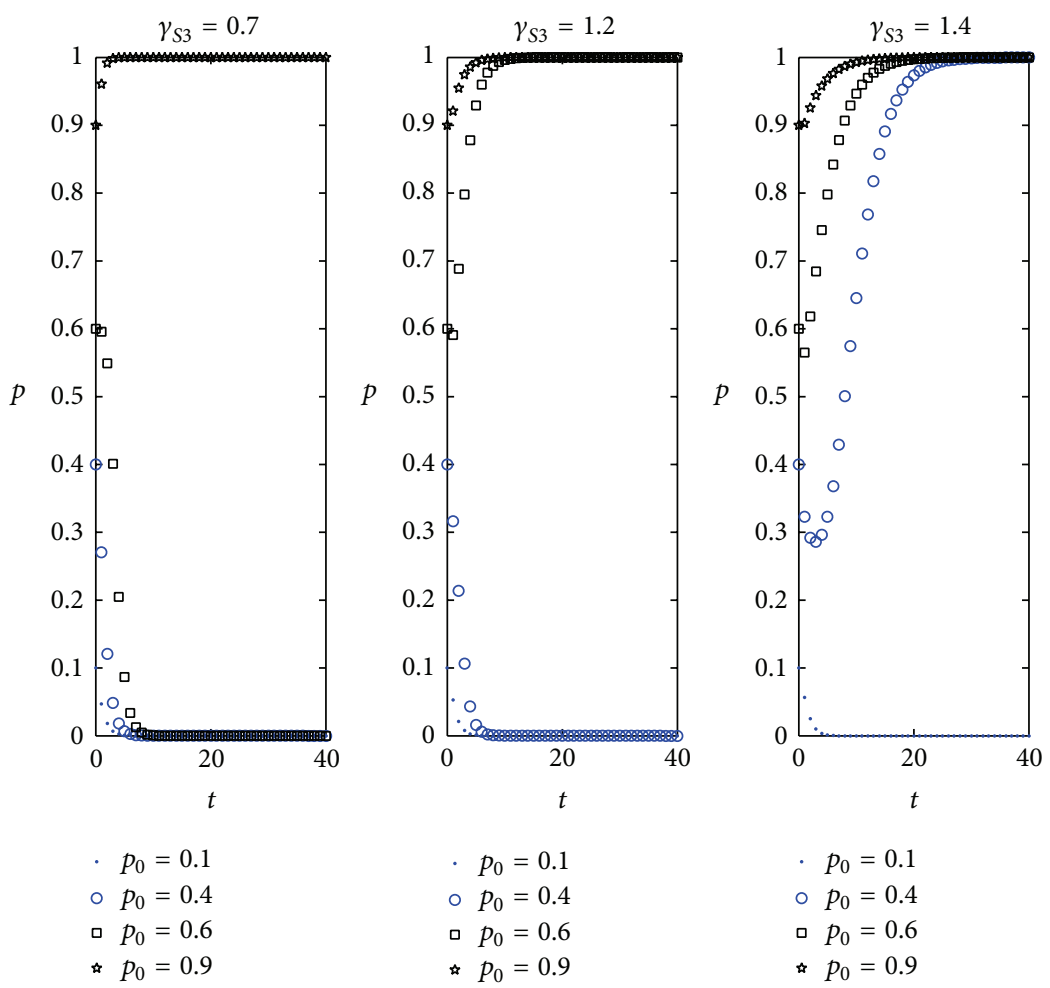

$\begin{aligned} \text { - } p_{0} & =0.1 \\ \text { } & p_{0}=0.4 \\ \text { - } p_{0} & =0.6 \\ \text { - } p_{0} & =0.9\end{aligned}$

FIGURE 11: The influence of the change of $\gamma_{S 3}$ on the result of the system evolution.
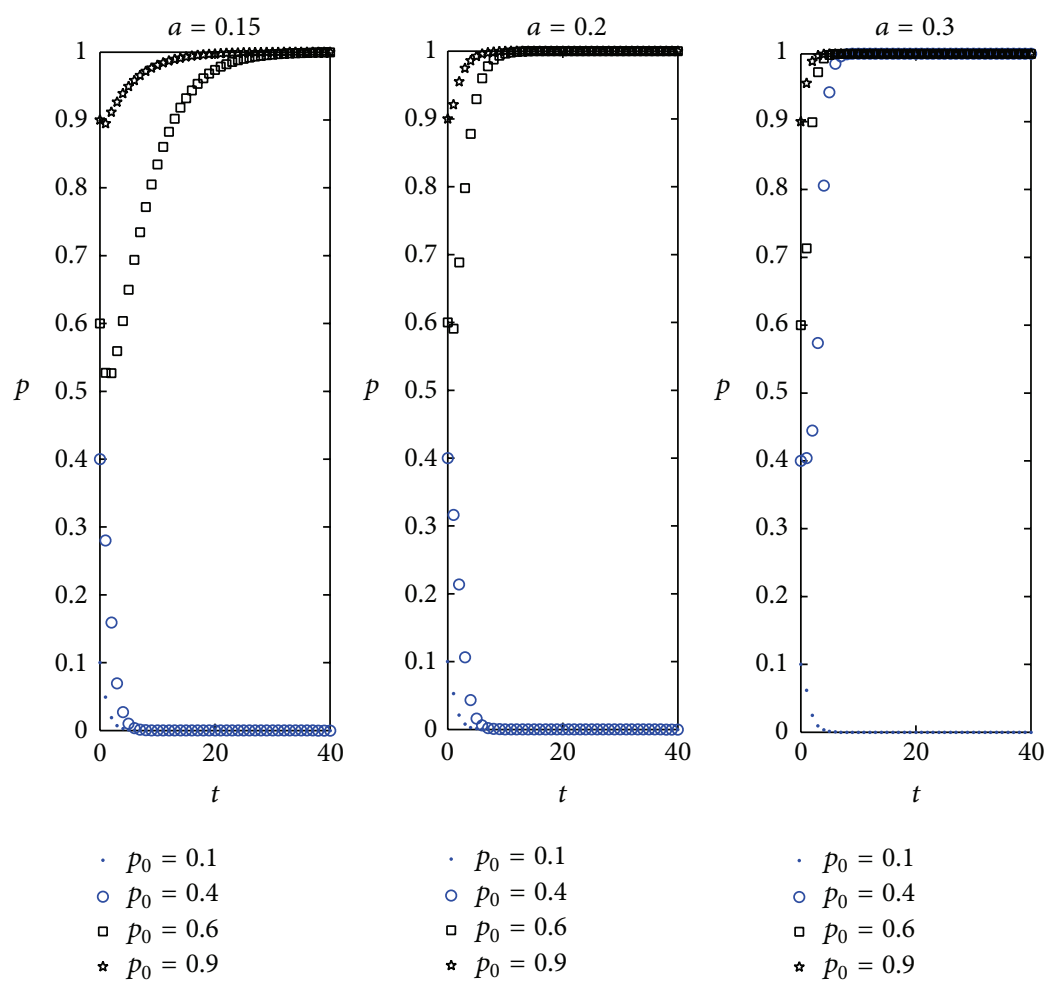

- $p_{0}=0.1$

- $p_{0}=0.4$

- $p_{0}=0.6$

* $p_{0}=0.9$

FIGURE 12: The influence of return coefficient $\alpha$ of university entrepreneurship training on system convergence. 
pressure, and by conducting entrepreneurial education and training, to inspire students' entrepreneurial enthusiasm and encourage students' entrepreneurship. The purpose of cultivating the ability of entrepreneurship is not only to encourage students to take part in the entrepreneurial activities during their stay in school or after graduation, but also to focus on the implementation of the students' entrepreneurial potential and help students accumulate human capitals and entrepreneurial energy stored for appropriate time for future.

\section{Conclusion}

Entrepreneurial talent training needs students' positive participation. The purpose of this research is to investigate the interaction between universities and students in the process of students' entrepreneurial ability training and the system evolution law, in order to find effective strategies for promoting the enthusiasm and initiative of university students' entrepreneurial ability.

Through the construction of payoff matrix of students' behavior, the evolution of behavior interaction system, its equilibrium, and the influence of different parameters on the system convergence are analyzed. The MatLab software is used for the results of numerical experiments under different parameters of the evolution system. We found that modes $\left(M_{Y}, N_{Y}\right)$ and $\left(M_{N}, N_{N}\right)$ are two evolutionary stable strategies by the interaction between universities and students, and the mode $\left(M_{N}, N_{N}\right)$ is badly locked.

At present, students' understanding of entrepreneurial ability is insufficient. There exist some negative attitudes toward entrepreneurship education activity, which is not conducive to the improvement of students' entrepreneurial ability. Model analysis and numerical experiment show that the system can evolve towards ideal pattern through improving the initial proportion of the positive involvement of group selection of entrepreneurial talent training in universities, reducing investment cost of universities' entrepreneurship, increasing the rate of return of universities' entrepreneurship education, stressing the investment on higher knowledge and ability, or increasing the efficiency of the entrepreneurial ability training to promote the reward rate of both universities and students.

\section{Conflict of Interests}

The authors declare that there is no conflict of interests regarding the publication of this paper.

\section{Acknowledgments}

This work was supported in part by the National Natural Science Foundation of China under Grants 71373104 and 71171099, the Jiangsu Philosophy and Societal Science Research Project under Grants 2012SJB630010 and 2012SJB880021, the Soft Science Research Project of Zhenjiang City under Grant YJ2012005, and the College Students' Ideological and Political Education Project of Jiangsu University under Grant JDXGCB201305.

\section{References}

[1] G. Gorman, D. Hanlon, and W. King, "Some research perspectives on entrepreneurship education, enterprise education and education for small management: a ten year literature review," International Small Business Journal, vol. 15, no. 3, pp. 56-77, 1997.

[2] A. Fayolle, Handbook of Research in Entrepreneurship Education, Edward Elegar, Northampton, Mass, USA, 2007.

[3] A. O'Connor, "A conceptual framework for entrepreneurship education policy: meeting government and economic purposes," Journal of Business Venturing, vol. 28, no. 4, pp. 546-563, 2013.

[4] R. T. Harrison and C. M. Leitch, "Entrepreneurship and leadership: the implication for education and development," Entrepreneurship and Regional Development, vol. 6, no. 2, pp. 111-125, 1994.

[5] S. L. Jack and A. R. Anderson, "Entrepreneurship education within the enterprise culture: producing reflective practitioner," International Journal of Entrepreneurial Behavior and Research, vol. 5, no. 3, pp. 110-125, 1999.

[6] J. O. Fiet, "The theoretical side of teaching entrepreneurship," Journal of Business Venturing, vol. 16, no. 1, pp. 1-24, 2001.

[7] C. A. Kent and L. P. Anderson, "Social capital, social entrepreneurship and entrepreneurship education," International Journal of Entrepreneurship Education, vol. 2, no. 1, pp. 41-59, 2004.

[8] D. A. Shepherd, "Educating entrepreneurship students about emotion and learning from failure," Academy of Management Learning and Education, vol. 3, no. 3, pp. 274-287, 2004.

[9] K. Sudharson, A. M. Ali, and A. M. Sermakani, "An organizational perspective of knowledge communication in developing entrepreneurship education for engineering students," Procedia: Social and Behavioral Sciences, vol. 73, no. 27, pp. 590-597, 2013.

[10] B. Johannisson, H. Landstrom, and J. Rosenberg, "University training for entrepreneurship-an action frame of reference," European Journal of Engineering Education, vol. 23, no. 4, pp. 477-496, 1998.

[11] D. Friedman, "Evolutionary games in economics," Eomomica, vol. 59, no. 3, pp. 637-666, 1991.

[12] Z.-H. Sheng and D.-P. Jiang, Evolutionary Economics, Shanghai Joint, Shanghai, China, 2002. 


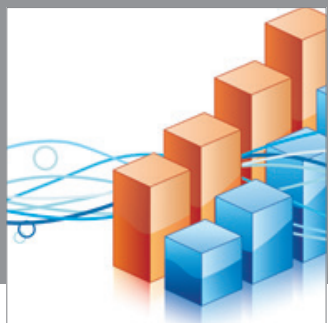

Advances in

Operations Research

mansans

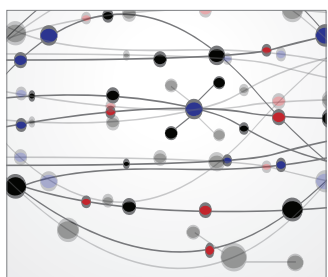

The Scientific World Journal
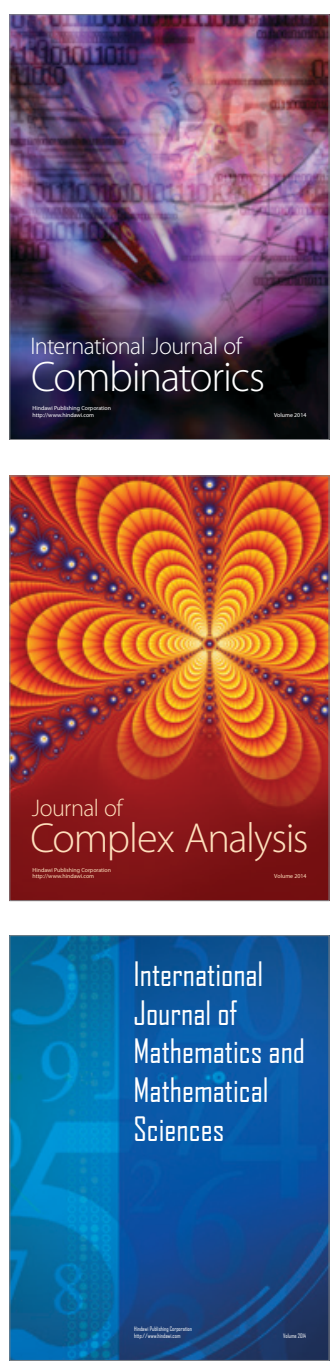
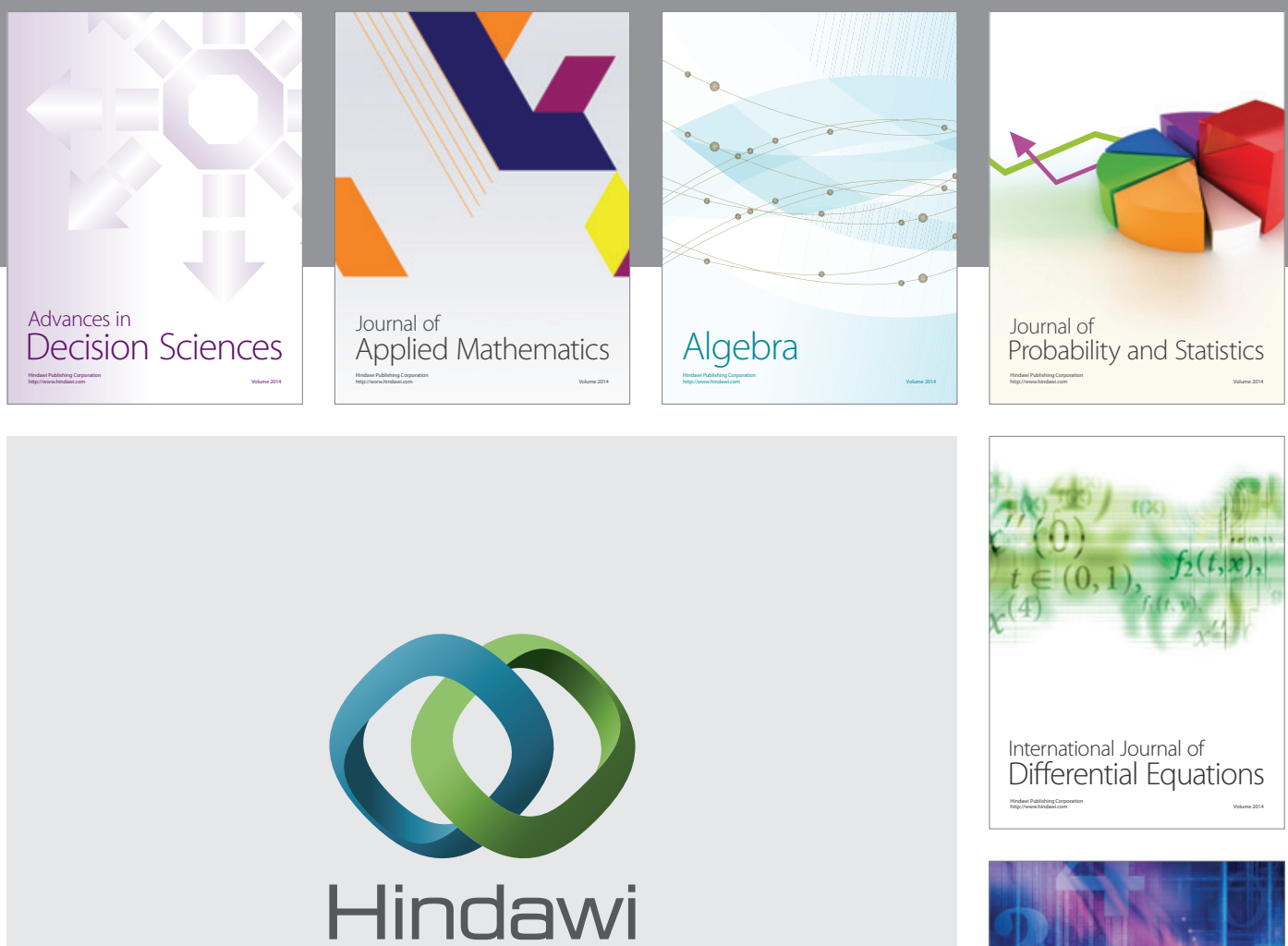

Submit your manuscripts at http://www.hindawi.com
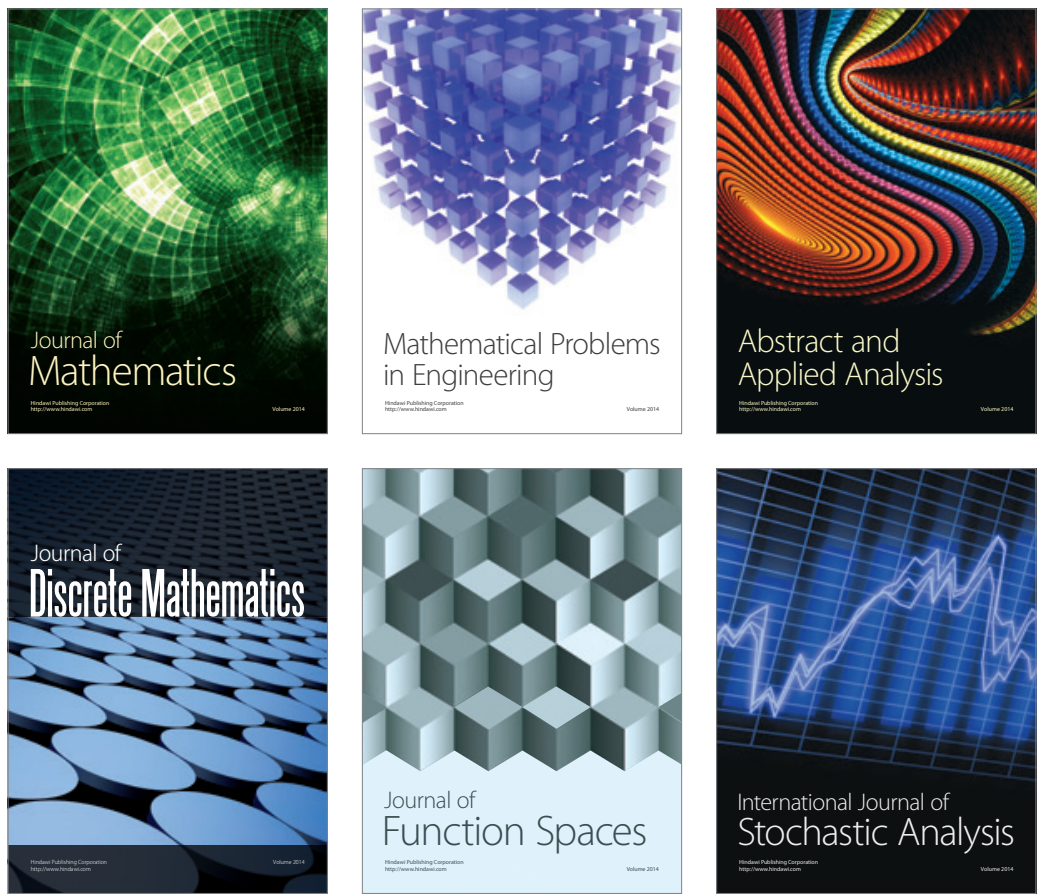

Journal of

Function Spaces

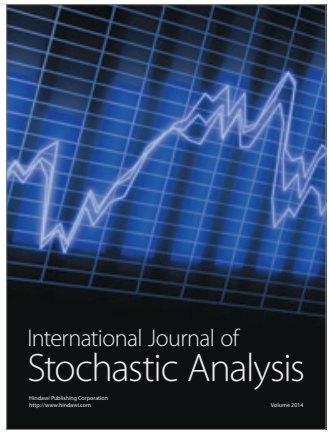

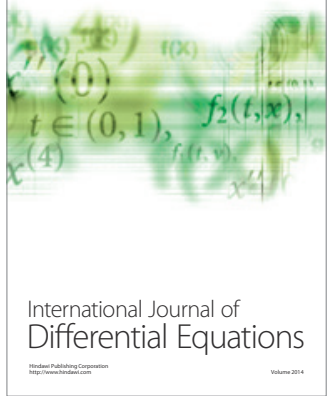
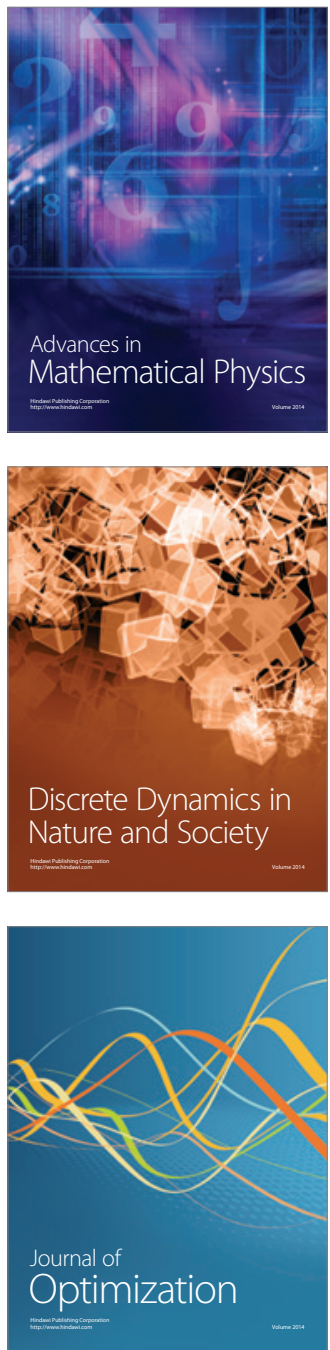